Published by Al-Nahrain College of Medicine P-ISSN 1681-6579

E-ISSN 2224-4719

Email: iraqijms@colmed-alnahrain.edu.iq

http://www.colmed-alnahrain.edu.iq

http://www.iraqijms.net

Iraqi JMS 2018; Vol. 16(4)

\title{
Comparing Dialysis Patients According to Estimated Glomerular Filtration Rate at Dialysis Initiation and Five Years Outcome
}

\author{
Jwad A. A. Al-Joher MMedSc Nephrology \\ ${ }^{1} \mathrm{Al}$-Yarmouk Teaching Hospital, Baghdad, Iraq
}

\begin{abstract}
Background

Objective

Methods
\end{abstract}

Results

Conclusion

Keywords

Citation

\begin{abstract}
It is not clear on which level of estimated glomerular filtration rate to start dialysis until now.
To compare between patient groups according to estimated glomerular filtration rate at dialysis initiation.
\end{abstract}

Eighty-seven Patients are selected randomly from a list of patients admitted for dialysis (Hemodialysis or Peritoneal dialysis) at Northern General Hospital - Sheffield Kidney Institute from $1^{\text {st }}$ of January to $31^{\text {st }}$ of December 2000. Patients have been categorized into two groups. First group includes 45 patients started dialysis with glomerular filtration rate less than $5 \mathrm{ml} / \mathrm{min} / 1.73 \mathrm{~m}^{2}$. Second group includes 42 patients started dialysis with glomerular filtration rate from $5-10 \mathrm{ml} / \mathrm{min} / 1.73 \mathrm{~m}^{2}$. Patients have been followed up for five years retrospectively until 31 $1^{\text {st }}$ December 2005.

The study showed males are the predominant gender. White Caucasian patients are majority of patients. The mean age is 56 years. About half of patients are middle aged (45-65 years) and are overweight or obese. This study shows no difference between patients who started dialysis early (estimated glomerular filtration rate 5 $10 \mathrm{ml} / \mathrm{min} / 1.73 \mathrm{~m}^{2}$ ) versus late (estimated glomerular filtration rate below $5 \mathrm{ml} / \mathrm{min} / 1.73 \mathrm{~m}^{2}$ ) in term of mortality and morbidity throughout five years of follow up.

This study showed no justification to decide on time to initiate dialysis based solely on estimated glomerular filtration rate level.

Chronic kidney disease, estimated glomerular filtration rate, hemodialysis, peritoneal dialysis, end stage renal disease, renal replacement therapy

Al-Joher JAA. Comparing dialysis patients according to estimated glomerular filtration rate at dialysis initiation and five years outcome. Iraqi JMS. 2018; 16(4): 413-423. doi: 10.22578/IJMS.16.4.9
List of abbreviations: CANUSA study = Canada-USA multicenter study of peritoneal dialysis adequacy, CKD = Chronic kidney disease, $\mathrm{CPD}=$ Chronic peritoneal dialysis, $\mathrm{DM}=$ Diabetes mellitus, eGFR = estimated Glomerular Filtration Rate, ESRD = End stage renal disease, $\mathrm{HD}=$ Hemodialysis, $\mathrm{KDIGO}=$ Kidney disease: Improving global outcomes, $\mathrm{Kt} / \mathrm{V}=\mathrm{K}$ dialyzer clearance of urea, $\mathrm{t}$ dialysis time, $\mathrm{V}$ volume of distribution of urea, $\mathrm{MD}=$ Maintenance dialysis, $\mathrm{MDRD}=$ Modification of diet in renal disease, $\mathrm{MHD}=$ Maintenance hemodialysis, NHANES = National Health and Nutrition Examination survey, NKF-K/DOQI = The National Kidney Foundation Kidney Disease Outcomes, PD $=$ Peritoneal dialysis, PTH $=$ Parathyroid hormone, RRT = Renal replacement therapy, SD = Standard deviation

\section{Introduction}

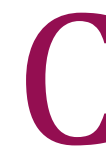

hronic kidney disease (CKD) is a worldwide public health problem. There were estimated to be over 37,800 adult patients receiving renal replacement therapy
(RRT) in the UK at the end of 2004. Haemodialysis (HD) was the very first modality of RRT in $71.0 \%$ of patients, peritoneal dialysis (PD) in $26.5 \%$ and preemptive transplant in $2.3 \%$, which compares with $58 \%$ starting HD in $1998^{(1)}$.

The glomerular filtration rate (GFR) is equal to the sum of the filtration rates in all of the functioning nephrons; thus, the GFR gives a rough measure of the number of functioning nephrons. A reduction in GFR implies either progression of the underlying disease or the development of a superimposed and often reversible problem, such as decreased renal perfusion due to volume depletion ${ }^{(2)}$. 
Estimated GFR $\left(\mathrm{mL} / \mathrm{min} / 1.73 \mathrm{~m}^{2}\right)$

$=186 \times(\mathrm{SCr})-1.154 \times($ Age $)-0.203 \times(0.742$ if female) $X$ (1.210 if African-American)

$=\exp (5.228-1.154 X \ln (\mathrm{SCr})-0.203 \times \ln (\mathrm{AGE})-$ 0.299 if female) + (0.192 if African-American))

Based on data from NHANES III, the the National Kidney Foundation (NKF)-Dialysis Outcome Quality Initiative (NKF-K/DOQI) CKD Guidelines workgroup estimated GFR using the equation derived from the MDRD Study, which factors in age, gender, race, and serum creatinine level ${ }^{(3,4)}$.

The timing of starting a dialysis modality may be due to a number of factors. Most commonly it is the increasing presence of symptoms that triggers the commencement of dialysis, and generally this will correspond to a decline in kidney function measured by GFR. Some patients will develop sever fluid retention unresponsive to diuretic therapy or electrolyte disturbances, particularly hyperkaliemia, that requires dialysis to start in the absence of symptoms. The other trigger is decline in eGFR even in the absence of symptoms. However, this may not always be accepted by patients who do not feel unwell (5).

Early guidelines outlined by the NKF-K/DOQI recommended that renal replacement therapy be considered when GFR declined below 10.5 $\mathrm{ml} / \mathrm{min} / 1.73 \mathrm{~m}^{2}$, and definitely implemented if there was unintentional weight loss, a decrease in normalized protein intake, or there were clinical signs or symptoms of uremia ${ }^{(6)}$.

The NKF 2006 update of clinical practice guidelines highlights the need for nephrologists to evaluate the risks and benefits of dialysis initiation when patients reach stage 5 CKD (estimated GFR $<15 \mathrm{ml} / \mathrm{min} / 1.73 \mathrm{~m}^{2}$ ) while acknowledging the importance of individual patient factors and their influence on the timing of dialysis. In Canada, clinical practice guidelines recommend dialysis initiation at a $\mathrm{GFR}<12 \mathrm{ml} / \mathrm{min} / 1.73 \mathrm{~m}^{2}$ if there is evidence of uremia or malnutrition or at a GFR $<6 \mathrm{ml} / \mathrm{min}$ whether symptomatic or not ${ }^{(7)}$.

Despite these guidelines, there appears to be a wide variation in the level of renal function at hemodialysis initiation and many patients continue to start dialysis at very low levels of predicted GFR. For example, Obrador et al. reported a mean predicted GFR of $7.1 \mathrm{ml} / \mathrm{min} /$ $1.73 \mathrm{~m}^{2}$ among new dialysis starts in the United States from April 1995 through September 1997 , and as many as $23 \%$ were considered late starts as defined by a GFR of $<5$ $\mathrm{mL} / \mathrm{min} / 1.73 \mathrm{~m}^{2}(8)$.

On the other hand, it is becoming increasingly clear from observational registry data from the United States that patients with comorbidities initiate dialysis therapy at higher levels of estimated GFR ${ }^{(9)}$.

In 2003, mean estimated GFR at the initiation of dialysis therapy was $9.8 \mathrm{~mL} / \mathrm{min} / 1.73 \mathrm{~m}^{2}$. This mean value reflects lower average values ( 7 to $9 \mathrm{~mL} / \mathrm{min} / 1.73 \mathrm{~m}^{2}$ ) for young and middle-aged adults and higher average values ( 10 to $10.5 \mathrm{~mL} / \mathrm{min} / 1.73 \mathrm{~m}^{2}$ ) for children and elderly patients. Average GFR at initiation has increased in all age groups since 1995; it has increased most in the oldest patients ${ }^{(10)}$.

It is difficult to make a recommendation for initiating RRT based solely on a specific level of GFR. Several studies concluded that there is no statistically significant association between renal function at the time of initiation of RRT and subsequent mortality (12-15). However, others suggested that worse kidney function at initiation of RRT is associated with increased mortality or morbidity (11-16).

The purpose of this study, to resolve the dilemma of when to start dialysis to patients with end stage kidney disease. This study might help to give answer to controversial opinions on level of eGFR to initiate patient on dialysis modality when starting dialysis early have suggested that it may improve nutrition with subsequent decrease in hospitalization, mortality, and costs. On the other hand, early initiation of dialysis poses ongoing diet and fluid restrictions, imposes limits on travel, impacts on patient and family quality of life, while exposing the individual to complications of dialysis earlier than may be necessary. 


\section{Methods}

The study is to compare between patient's groups according to initial eGFR (MDRD calculation) in term of followings points:

- Patients' demography

- Retrospectively follow up of patients for 5 years to study dialysis outcome in term of mortality, anemia, bone biochemistry, lipid, Blood pressure, Kt/V ( $\mathrm{K}$ dialyzer clearance of urea, $t$ dialysis time, $V$ volume of distribution of urea), and albumin as nutrition status marker with body mass index (BMI).

- Survival of patients and its association with covariates of study for each group of patients

- Hospitalization in form of number of admissions to hospital.

\section{Patients}

Patients are selected randomly from a list of patients admitted to dialysis (HD or PD) at Northern General Hospital - Sheffield Kidney Institute from $1^{\text {st }}$ of January to $31^{\text {st }}$ of December 2000. The list of patients (provided by Sheffield Kidney Institute Academic office) is randomly sorted by patients' hospital code numbers, which consists of six digital numbers. Patients should have been on any dialysis modalities for more than 90 days to be considered to have chronic disease and not acute phase of kidney disease. Any patients who have had dialysis for more than three months before 2000 were excluded. Ninety patients were selected by simple random selection, only 3 patients have initiated dialysis with eGFR more than $10 \mathrm{ml} / \mathrm{min} / \mathrm{m}^{2}$ and they were excluded from this study because of their small number. Eighty-seven patients were divided into two groups according to baseline eGFR. Group 1, consists of 45 patients with baseline eGFR less than $5 \mathrm{ml} / \mathrm{min} / 1.73 \mathrm{~m}^{2}$. Group 2 are 42 patients with baseline estimated GFR $5-10 \mathrm{ml} / \mathrm{min} / 1.73 \mathrm{~m}^{2}$. Patients have been followed up for five years retrospectively until 31 $1^{\text {st }}$ of December 2005.

\section{Data collection}

Approval to access patient's information was obtained. Username and password were provided by Northern General Hospital Sheffield Kidney Institute Academic office. All patients' data were accessed through Proton program, which installed on computer systems at Health Sciences Library, Samuel Fox House and Study Room 4, Coleridge House at Northern General Hospital. Retrospectively, data were collected. The list of patients was provided by Sheffield Kidney Institute to patients admitted for dialysis in year 2000 . The list contains patients' code numbers in form of six digits ( $x x x x x x)$. Randomly selected patient's code number, entered into Proton program to access patient's information.

Using Excel office program for Windows helps to enter data, and organizes work. Age of patients is calculated which represents age in years from date of birth to date of dialysis.

Patients' demographic parameters (age in years, gender as male or female, and ethnicity) are obtained. BMI is calculated from weight of patient in Kilogram divided by square height of patient in meter.

eGFR is recorded at time starting dialysis. MDRD equation is used to eGFR. Serum creatinine at day of dialysis, age of patient, gender and race are all recorded and entered in MDRD equation to calculate estimated GFR.

Underlying cause of ESRD is recorded. It includes diabetic nephropathy, glomerulonephritis, hypertension, renovascular disease, cystic disease, obstructive uropathy and others like lupus nephritis, Alport disease, and analgesic nephropathy...etc. Uncertain underlying causes is also recorded.

Type of dialysis modalities patients started on either HD or PD is recorded. Hemodialysis machine type is Fresenius 2008K, and FX800 dialyzer are used. During following up patients, mortality, switch of modality and change of renal replacement therapy into transplantation are recorded with the date of each event to calculate years each patient spends on dialysis. Moreover, date of referral to Sheffield Kidney 
institute is recorded down and period from first referral to date of dialysis is calculated.

Comorbidity, which includes cardiovascular disease, cerebrovascular accident, cancer, access line complications and diabetes are all recorded. Patients with smoking history are considered as a smoker regardless of quantity of smoking. Number of admission and causes of admission to hospital is recorded for five years since started dialysis.

In both groups, mean value for variables were recorded for each patient on each year and for five years. The followings are variables that were taken:

- Hemoglobin level in $\mathrm{g} / \mathrm{dl}$ is taken as indicator for anemia.

- Albumin in g/l nutritional status.

- Serum calcium level in $\mathrm{mmol} / \mathrm{l}$, parathyroid hormone (PTH) in $\mathrm{ng} / \mathrm{l}$, Phosphate in $\mathrm{mmol} / \mathrm{L}$ are taken as indicator for bone disease.

- $\mathrm{Kt} / \mathrm{V}$ is recorded reflecting adequacy of dialysis for both HD and PD.

- Systolic and Diastolic blood pressure

- HbA1c percentage for diabetic patients

- Serum cholesterol and triglyceride in $\mathrm{mmol} / \mathrm{l}$

\section{Statistical analysis}

The IBM Statistical Package for the Social Sciences (SPSS) program version 15 (installed on Microsoft Windows operating system) is used for statistical analysis of data. Parametric independent simple t-test is used to compare between mean values. Cross tables are formed and Chi square test is used to study difference between the two groups for categorical data. Continuous variables are changed into binary variable (0 and 1$)$. The followings are cutoff points used based on Kidney Disease Improving Global Outcomes (KDIGO) guidelines (www.kdigo.org) (17):

Patients have Hemoglobin below $11 \mathrm{~g} / \mathrm{dl}$ assigned as 1 , and 0 for 11 and above. Patients have albumin less than $30 \mathrm{~g} / \mathrm{L}$ assigned as 1 , and 0 to albumin level 30 or more. Calcium more than $2.6 \mathrm{mmol} / \mathrm{l}$ is considered as high, more than $1.8 \mathrm{mmol} / \mathrm{l}$ for phosphate and more than $300 \mathrm{ng} / \mathrm{L}$ for PTH. Patients on HD with $\mathrm{Kt} / \mathrm{v}$ with 1.2 and more are achieved KDIGO target. In other hand, 2 is target for PD patients. Blood pressure above $130 / 80$ is considered as high value. $\mathrm{HbA1c}$ more than or equal to $7 \%$ is taken as poor control for diabetic patients. More than $5 \mathrm{mmol} / \mathrm{l}$ for cholesterol and $1.69 \mathrm{mmol} / \mathrm{l}$ for triglycerides. Cox Regression is used to study covariates with years of survival with $P$ value of less than 0.05 is considered significant. Hospitalization studied using number of admissions with linear Regression model. P value less than 0.05 is considered significant. Linear Regression is used to study number of admission to hospital and covariates

\section{Results}

Ninety patients are fulfilled criteria of the study, 3 patients have baseline eGFR $>10$, these patients were excluded from statistical analysis due to small number. Eighty-Seven patients are divided into two groups according to Baseline estimated GFR. Group 1 with eGFR less than 5 $\mathrm{ml} / \mathrm{min} / 1.73 \mathrm{~m}^{2}$ consists of 45 patients who represent 52\%. Group 2 with eGFR between 5 $10 \mathrm{ml} / \mathrm{min} / 1.73 \mathrm{~m}^{2}$ consists of 42 patients (48\%).

\section{Patients' demography}

Two groups did not show any significant difference in age of patients. Males are predominant in both groups and represent $68 \%$, while females are $32 \%$. Statistical analysis shows no significant difference in gender between two groups. White Caucasians are a majority of patients and represents $94 \%$. There are no significant differences between the two groups. There are no significant differences in $\mathrm{BMI}$ and number of smokers between the two groups (Table 1 ).

\section{Underlying cause of ESRD}

Diabetic nephropathy was the major cause of ESRD over all, and predominantly in group 2 as it shown in table 2. 
Table 1. Patients' demography

\begin{tabular}{ccccc}
\hline & Group 1 & Group 2 & Total & P value \\
\hline Number of patients & 45 & 42 & 87 & \\
\hline Mean Age & 56.71 & 56.8 & & \\
18- 44 years & $9(10 \%)$ & $8(10 \%)$ & $17(20 \%)$ & 0.97 \\
$45-65$ years & $22(25 \%)$ & $19(22 \%)$ & $41(47 \%)$ & 0.84 \\
$>65$ years & $14(16 \%)$ & $15(17 \%)$ & $29(33 \%)$ & 0.63 \\
\hline Male & $28(32 \%)$ & $31(36 \%)$ & $59(68 \%)$ & 0.62 \\
Female & $17(19 \%)$ & $11(13 \%)$ & $28(32 \%)$ & 0.91 \\
\hline Caucasian & $42(48 \%)$ & $40(46 \%)$ & $82(94 \%)$ & 0.66 \\
Asian & $3(3 \%)$ & $2(3 \%)$ & $5(6 \%)$ & 0.78 \\
\hline Mean BMI & 25.434 & 25.718 & & \\
Underweight $(<18.5)$ & $2(2 \%)$ & $2(2 \%)$ & $4(5 \%)$ & 0.71 \\
Normal $(18.5-24.9)$ & $22(25 \%)$ & $22(25 \%)$ & $44(50 \%)$ & 0.82 \\
Overweight $(25-29.9)$ & $12(13 \%)$ & $10(12 \%)$ & $22(25 \%)$ & 0.6 \\
Obese $>30$ & $9(10 \%)$ & $8(10 \%)$ & $17(20 \%)$ & 0.94 \\
\hline Smoker & $10(12 \%)$ & $10(12 \%)$ & $20(24 \%)$ & 0.86 \\
\hline
\end{tabular}

Table 2. Underlying causes of ESRD in the two groups

\begin{tabular}{cccc}
\hline Underlying cause & $\begin{array}{c}\text { Group 1 } \\
\text { No. (\%) }\end{array}$ & $\begin{array}{c}\text { Group 2 } \\
\text { No. (\%) }\end{array}$ & Total \\
\hline Diabetic nephropathy & $2(4 \%)$ & $16(17 \%)$ & $18(21 \%)$ \\
Glomerulonephritis & $7(8 \%)$ & $1(1 \%)$ & $8(9 \%)$ \\
Hypertension & $3(4 \%)$ & $4(4 \%)$ & $7(8 \%)$ \\
Renovascular disease & $2(2 \%)$ & $1(1 \%)$ & $3(3 \%)$ \\
Cystic disease & $5(5 \%)$ & $4(5 \%)$ & $9(10 \%)$ \\
Obstructive uropathy & $4(5 \%)$ & $1(1 \%)$ & $5(6 \%)$ \\
Uncertain & $14(16 \%)$ & $6(7 \%)$ & $20(23 \%)$ \\
Others & $8(10 \%)$ & $9(10 \%)$ & $17(20 \%)$ \\
\hline
\end{tabular}

\section{Dialysis modality}

From both groups (Group 1 and Group 2), 49\% of patients are on HD and $51 \%$ patients are on PD. In group 1, there are 22 (25\%) patients on HD, while $23(26 \%)$ patients are on PD. In Group 2, 21 (24\%) patients are on HD and 21 (24\%) patients are on PD. There are no significant differences in dialysis modalities between both groups (Pearson chi-square significant $=0.918$ ).

\section{Fate of patients}

During five years of follow up, $31 \%$ of patients died, $18 \%$ have had transplanted kidney and $21 \%$ of them changed dialysis modality from PD to HD. Mean survival is $3.6 \pm 1.6$ SD years for group1 and 3.3 \pm 1.7 SD years for group2. Comparing mean values of survival years showed no statistic significant ( $P$ value $=0.398$ ). During the first year, from date of dialysis, four (4\%) patients died from group 1, and five (5\%) from group 2 . In the second year, three (3\%) patients died from group 1, and four (4\%) from group 2 . In the third year, one (1\%) patient 
died from group 1 and 3 (3\%) from group2. In the fourth year, 4 (4\%) patients died from group1 while 3 (3\%) patients died from group 2. Statistical analysis did not show any significant differences in number of deaths during the first, second, third and fourth year of follow up (Pearson Chi-square significant are $0.694,0.282,0.280$, and 0.235 respectively).
There were no deaths recorded during the fifth year. There were no significant differences in the number of patients that have had a transplanted kidney and patients who changed PD into HD between group 1 and 2 (Pearson Chi-Square significant are 0.131 , and 0.371 respectively) (Table 3 ).

Table 3. Fate of patients in form of mortality, transplantation and switch modality

\begin{tabular}{cccc}
\hline Fate & $\begin{array}{c}\text { Group 1 } \\
\text { No. (\%) }\end{array}$ & $\begin{array}{c}\text { Group 2 } \\
\text { No. (\%) }\end{array}$ & Total \\
\hline Mortality & $12(14 \%)$ & $15(17 \%)$ & $27(31 \%)$ \\
Transplanted & $11(12 \%)$ & $5(6 \%)$ & $16(18 \%)$ \\
Switch modality & $11(12 \%)$ & $7(9 \%)$ & $18(21 \%)$ \\
\hline
\end{tabular}

\section{Comorbidity}

Thirty percent of patients have Diabetes Mellitus (Figure 1), $30 \%$ of patients have history of myocardial infarction or ischemic heart disease, $6 \%$ of them have cancer. One patient has renal tumor as a primary cause of ESRD, other four patients have extra renal tumors. Seventeen percent of patients have had a stroke.

\section{Anemia}

Statistical analysis shows significant differences between the two groups in the first year of follow up. Group 1 is significantly lower in mean Hemoglobin than group 2 in the first year (Independent simple $t$ test $=0.19$ ). The rest of the follow up years did not show any statistical significance in mean values of serum hemoglobin between the two groups (independent simple $t$ test are 0.599, 0.77, $0.81,0.83$ in second, third, fourth and fifth year respectively) (Table 4$)$.
Calcium, hosphate, and parathyroid hormone: For Mean Serum Calcium level, statistical analysis shows no difference between group 1 and 2 on each year of follow up ( $P$ values 0.7 , $0.5,0.9,0.8,0.6$ respectively). Mean Serum Phosphate and PTH again no difference between the two groups on each year of follow up $(P$ values for phosphate are $0.07,0.3,0.2$, 0.7 , and 0.6 and for PTH are 0.4, 0.2, 0.2, 0.09, 0.2 respectively).

\section{Cholesterol and triglyceride}

Comparing the two groups, $\mathrm{P}$ values for Mean Cholesterol on each year of follow up are 0.2 , $0.7,0.3,0.5,0.3$. $P$ values for Mean Triglyceride are 0.4, 0.2, 0.1, 0.2 and 0.09. Mean Cholesterol and Triglyceride do not show statistic significant difference between group 1 and 2 . Forty-eight $\%, 32 \%, 33 \%, 16 \%, 11 \%$ of patients have Cholesterol above target and $69 \%, 73 \%, 68 \%, 63 \%, 47 \%$ of patients have Triglyceride above target on each year of follow up respectively. 


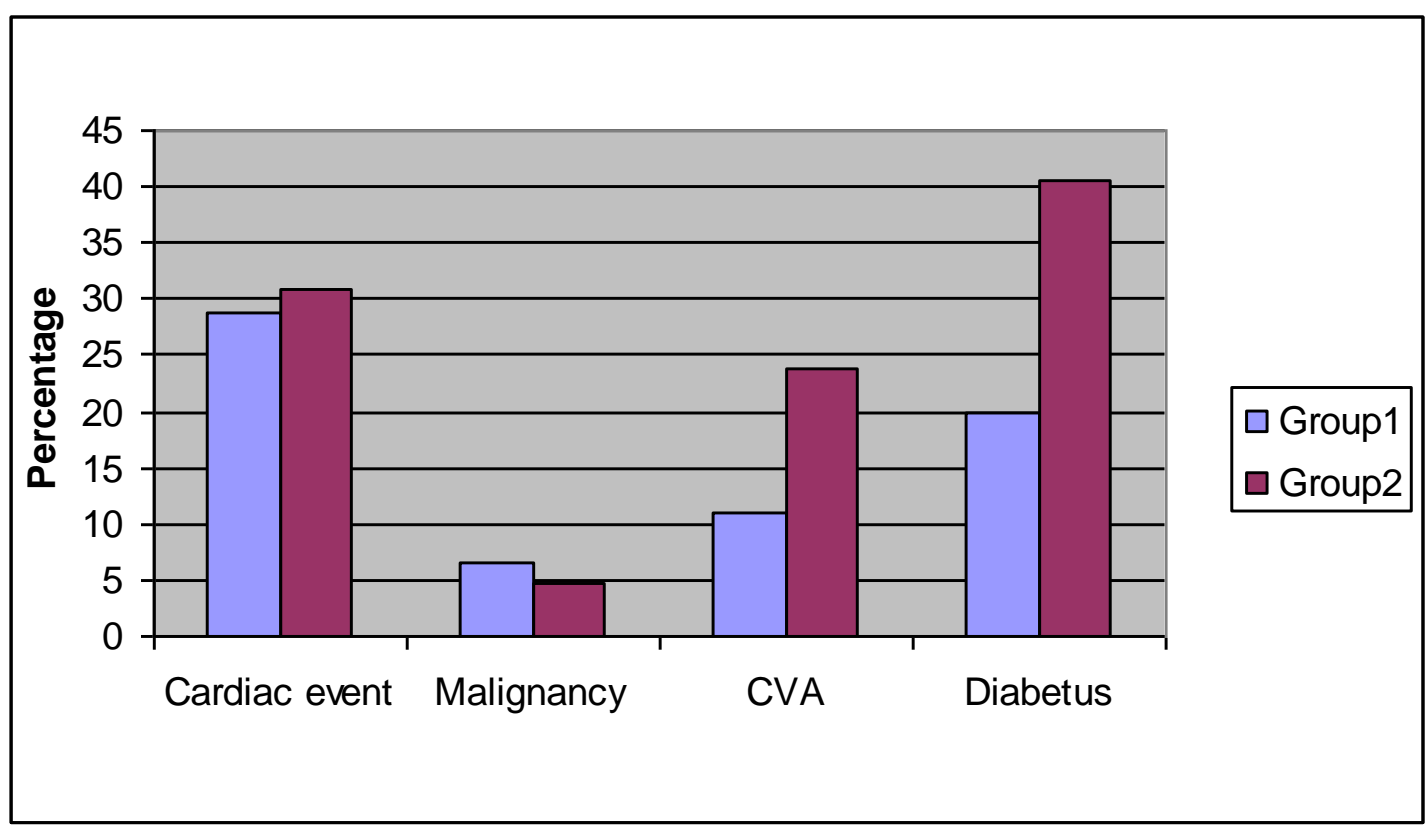

Figure 1. Comorbidity; cardiac events (myocardiac infarction, ischemic heart disease), cancer, CVA (Cerebrovascular accident), and diabetes in both groups

Table 4. Mean value for Serum Hemoglobin on each year of follow up

\begin{tabular}{cccc}
\hline Year & \multicolumn{2}{c}{ Mean Hb g/dl } & P value \\
\hline 1 & Group 1 & Group 2 & 0.19 \\
2 & 9.6 & 10.2 & 0.599 \\
3 & 10.9 & 11 & 0.77 \\
4 & 11.3 & 11.2 & 0.81 \\
5 & 11.4 & 11.3 & 0.83 \\
\hline
\end{tabular}

\section{Albumin}

Statistical analysis shows no significant differences in mean Albumin between the two groups in all years except the third year when statistical analysis showed a significant difference ( $P$ value in each year of follow up as following:0.3, 0.5, 0.01, 0.1, 0.3). Sixteen \%, $14 \%, 24 \%, 29 \%, 31 \%$ of patients have Albumin level below the target during each year of follow up respectively.

\section{Systolic and diastolic blood pressure:}

No statistic significances between the two groups in Mean systolic and diastolic blood pressure during the five years ( $P$ value $0.6,0.2$, $0.2,0.9,0.8$ for systolic, $0.4,0.2,0.9,0.2,0.1$ for diastolic). $82 \%, 68 \%, 77 \%, 79 \%, 74 \%$ of patients have systolic blood pressure higher than the target $(130 \mathrm{mmHg})$ during the first, second, third, fourth, and fifth year respectively. $35 \%, 51 \%, 46 \%, 30 \%, 36 \%$ of patients have diastolic blood pressure above the target $(80 \mathrm{mmHg})$ during years of follow up respectively.

\section{Hb1Ac}

Statistical analysis shows significant difference in mean $\mathrm{HbA} 1 \mathrm{c} \%$ during first, second and 
fourth year. Group 2 significantly have HbA1c\% higher than group 1 in these years ( $P$ value $0.025,0.041$, and 0.02 in first, second and fourth year) while no statistic significant in third and fourth year ( $P$ value $=0.2$ each). Eleven $\%, 10 \%, 9 \%, 4 \%$ and $4 \%$ of patients have uncontrolled diabetes level during first, second, third, fourth and fifth year respectively.

\section{$\mathrm{Kt} / \mathrm{V}$}

Forty-five percent of patients achieve Kt/V target in the first year. $62 \%, 60 \%, 80 \%$ and $80 \%$ of patients achieve Kt/ $\mathrm{V}$ target in second, third, fourth and fifth year respectively. No statistical significance between the two groups in the number of patients achieving Kt/v target during five years (Pearson Chi square $=0.072,0.410$, $0.934,0.945,0.631$ )

\section{Survival}

Cox Regression is used to study covariates with years of survival. Age shows statistic significant covariates with years of survival in both groups. $\mathrm{BMI}$ shows significant with group1. All other covariates show no statistical significance with survival of patients in both groups (Table 5).

Table 5. Covariates in both groups and survival (Cox Regression $P$ values)

\begin{tabular}{ccc}
\hline Covariates & Group 1 (P value) & Group 2 (P value) \\
\hline Age & 0.03 & 0.026 \\
BMI & 0.034 & 0.99 \\
Gender & 0.3 & 0.2 \\
Smoking & 0.9 & 0.7 \\
Dialysis modalities & 0.4 & 0.9 \\
Cardiovascular disease & 0.5 & 0.1 \\
Cancer & 0.5 & 0.3 \\
Cerebrovascular accident & 0.07 & 0.4 \\
Albumin & 0.5 & 0.2 \\
Calcium & 0.3 & 0.6 \\
Phosphate & 0.4 & 0.9 \\
PTH & 0.4 & 0.2 \\
Cholesterol & 0.8 & 0.2 \\
Triglyceride & 0.9 & 0.3 \\
Hemoglobin & 0.8 & 0.7 \\
Systolic blood pressure & 0.3 & 0.2 \\
Diastolic blood pressure & 0.9 & 0.3 \\
Diabetes & 0.7 & 0.6 \\
Years from referral to dialysis & 0.1 & 0.3 \\
Kt/V & 0.8 & 0.5
\end{tabular}

\section{Hospitalization:}

Mean number of admissions to hospital for group 1 is $3.4 \pm 3.6$ SD during five years and it is $3.1 \pm 3 \mathrm{SD}$. Independent simple t-test shows no significance between mean values of number of admission between the two groups $(P=0.623)$. Linear Regression is used to study number of admission to hospital and covariates. Statistical analysis shows smoking is a significant covariate in number of admission in group 1. Patients admitted for peritonitis at least once have significant statistical analysis in association with the number of admission in group 2. All other covariates do not show significance with number of admission of patients for both groups (Table 6). 
Iraqi JMS 2018; Vol. 16(4)

Table 6. $P$ values of number of admissions and covariates in linear regression analysis

\begin{tabular}{ccc}
\hline Covariates & Group 1 (P values) & Group 2 (P values) \\
\hline Age & 0.1 & 0.2 \\
Gender & 0.9 & 0.5 \\
BMI & 0.9 & 0.3 \\
Smoking & 0.04 & 0.3 \\
Dialysis Modalities & 0.2 & 0.1 \\
Cardiovascular disease & 0.6 & 0.1 \\
Cancer & 0.6 & 0.5 \\
Cerebrovascular accident & 0.3 & 0.08 \\
Peritonitis & 0.07 & 0.000 \\
Access line complication & 0.09 & 0.8 \\
Calcium & 0.3 & 0.8 \\
Phosphate & 0.5 & 0.5 \\
PTH & 0.5 & 0.6 \\
Diabetes & 0.9 & 0.2 \\
Cholesterol & 0.5 & 0.3 \\
Triglyceride & 0.2 & 0.5 \\
Systolic blood pressure & 0.9 & 0.7 \\
Diastolic blood pressure & 0.7 & 0.5 \\
Kt/v & 0.2 & 0.056 \\
Years from referral to dialysis & 0.1 & 0.1 \\
\hline
\end{tabular}

\section{Discussion}

In this study, about two third of patients are males and it is in the same proportion in the two groups. In addition, gender is not a predictor factor for survival or number of admissions for both groups. Majority of patients are white Caucasian patients represent $94 \%$. Small number of other ethnic group would not help as comparison group with white Caucasian group. Hence, ethnicity has not been studied as predictor for survival or number of admissions to hospital.

About half of patients are between $45-65$ years old, and one third of patients are more than 65 years old. Age is a predictor for survival of patients in both groups. It is not surprising that increase in age would increase risk of death and that was a predictor in both groups.

Natures of underlying causes that lead to end stage renal disease are variable. About twenty percent of patients' cause of renal disease is diabetic nephropathy. Diabetic nephropathy is highest underlying cause of end stage renal disease. Therefore, helping diabetic patients by preventing them from getting into this level of renal injury might save patients and health system from devastating complications, preserve quality of life and enormous money spend. Diabetic patients in group 2 were higher in number than group 1 and that might explain higher deaths in group 2 although it was not statistically significant. Moreover, glycemic control was worse in group 2 than group 1 predominantly in first year, and it could be explained by renal residual function and insulin clearance. The lower estimated GFR results in lower insulin clearance and hence lower glucose levels. Therefore, group 1 (eGFR lower than $5 \mathrm{ml} / \mathrm{min} / 1.73 \mathrm{~m}^{2}$ ) had lower glucose levels than group 2 .

Still underlying cause for a large number of patients is unidentifiable and that may give impression of late presentation with the disease when biopsy study would be useless. Smoking found as a covariate that predict number of admissions to hospital in group 1 
but not group 2. Though, Smokers are equally distributed in both groups and represent $23 \%$ of all patients.

Dialysis modalities are not a predictor for survival or number of admissions to hospital. Half of patients on HD and other half on PD and same proportions are applied to each group. Patients on hemodialysis would have access line complications like infection, bleeding, clotting or obstruction of line, on other hands, patients on peritoneal dialysis are reliable for peritonitis, exit site infection, drain problem or leakage of catheter and hernia. One of the drawbacks of this study is that it did not show differences in number of admissions in associated with dialysis modality. Access line complications are not a predictor for number of admissions in both groups. On the other hand, peritonitis is a predictor for number of admissions in group 2 only but not in group 1. Number of admissions is not enough to reflect hospitalization. This Study should have conducted duration of admission and cost for admissions and compare that between the two groups.

Despite of no statistic difference in number of deaths between the two groups of patients in each year of follow up, Lead time bias should have been considered in this study when patients' residual renal function might affect morbidity and mortality. Variety in residual renal function should have been taken in account in this study (i.e., would appear to increase survival of those individuals starting dialysis with more residual renal function).

Regarding hemoglobin level, improvements in the level of hemoglobin are shown in the next year with half of patients whom have hemoglobin below the target level. This can be explained by starting the patients on erythropoietin stimulating agents and Iron therapy which they were not exposed to them previously. Patients tend to present with lower hemoglobin level in group 1 in comparison with group 2 in first year of dialysis. Again patients with delay presentation would have lower level of Hemoglobin in comparison to the ones started dialysis and treated earlier.

The IDEAL (Imitating Dialysis Early and Late) study (Cooper et al, 2010) was landmark randomized controlled trial. This trial studied patients with early dialysis (eGFR 10-15 $\mathrm{ml} / \mathrm{min} / 1.73 \mathrm{~m}^{2}$ ) versus late dialysis (eGFR 5-7 $\mathrm{ml} / \mathrm{min} / 1.73 \mathrm{~m}^{2}$ ) ${ }^{(18)}$. There was no advantage in the early dialysis regarding mortality and morbidity in similar way to this study but the difference was the early dialysis group were with higher eGFR. Still the results were similar though.

Conversely, multiple retrospective analyses from multiple cohorts demonstrate that patients who start dialysis at lower eGFRs have better survival, compared to those who start with higher levels eGFRs (Sawhney et al, 2009; Wright et al, 2010; Clark et al, 2011) ${ }^{(19,20)}$.

This study concluded that it could not support or reject the hypothesis of early initiation of dialysis when all patients started dialysis with eGFR equal or below $10 \mathrm{ml} / \mathrm{min} / \mathrm{m}^{2}$ and not above this level. However, Patients started dialysis later with eGFR below showed worse anemia level than those with early initiation (eGFR between 5-10), which might give impression that early initiation of dialysis would avoid later complications. Since prolong history of anemia has dramatic effect on the heart and causing left ventricular hypertrophy. However, this tragedy can be definitely avoided by early correction of anemia and not necessarily an indication to start dialysis earlier per say.

On other hand, the group with earlier initiation of dialysis has worse glucose control than the ones started dialysis later and this is related to insulin clearance. However, this finding did not show death difference statically but the number of death were slightly higher though in the group with worse glycemic control.

With no significant difference in morbidity or mortality in patients with the group started dialysis early (eGFR 5-10) and whom started later (eGFR below 5), throughout the five years of follow up, there is no justification to decide on time to initiate dialysis based solely on eGFR level.

Statistical analysis has shown smoking in group 1 is the only predicator for number of admissions to hospital, while peritonitis is the predicator for group 2. 


\section{Acknowledgments}

Thanks to Mrs. Denis Smith, secretary at Northern General Hospital - Renal Unit, and to Miss Jean Russell for her help in statistical analysis.

\section{Conflict of interest}

No conflict of interest.

\section{Funding}

Self-funded.

\section{References}

1. Ansell D, Feest $T$, Rao R, et al (eds). The Renal Association UK Renal Registry. Eighth Annual Report. 2005.

2. Stevens LA, Levey AS. Measurement of kidney function. In: Singh AK (ed). Medical Clinics of North America. Philadelphia: W.B. Saunders; 2005; p. 457.

3. Levey, A, Bosch, J, Lewis, J, et al. A more accurate method to estimate glomerular filtration rate from serum creatinine: A new prediction equation. Ann Intern Med. 1999, 130(6): 461-70. doi: http://dx.doi.org/10.7326/0003-4819-130-6199903160-00002.

4. Kausz, AT, Obrador, GT, Arora, P, et al. Late initiation of dialysis among women and ethnic minorities in the United States. J Am Soc Nephrol 2000; 11(12): 23517.

5. Levey AS, Coresh J, Balk E, et al. National Kidney Foundation practice guidelines for chronic kidney disease: Evaluation, classification, and stratification. Ann Intern Med. 2003; 139(2): 137-47. doi: 10.7326/0003-4819-139-2-200307150-00013.

6. National Kidney Foundation. K/DOQI clinical practice guidelines for peritoneal dialysis adequacy. Am J Kid Dis. 1997, 30 (3, Suppl 2): S134-6.

7. Churchill DN, Blake PG, Jindal KK, et al. Clinical practice guidelines for initiation of dialysis. J Am Soc Nephrol. 1999;10 Suppl 13: S289-91.

8. Obrador GT, Arora P, Kausz AT, et al. Level of renal function at the initiation of dialysis in the U.S. endstage renal disease population. Kidney Int. 1999; 56(6): 2227-35. doi: 10.1038/sj.ki.4491163.

9. U.S. Renal Data System. USRDS 2005 Annual Data Report: Atlas of End-Stage Renal Disease in the United States, National Institutes of Health, National
Institute of Diabetes and Digestive and Kidney Diseases. Bethesda, MD.

10. Tattersall J, Greenwood R, Farrington K. Urea kinetics and when to commence dialysis. Am J Nephrol. 1995; 15(4):283-9. doi: 10.1159/000168850

11. US Renal Data System: USRDS 2004 Annual Data Report. The National Institutes of Health, National Institute of Diabetes and Digestive and Kidney Diseases, Bethesda, MD, 2004.

12. Ellis PA, Reddy V, Bari N, et al. Late referral of endstage renal failure. QJM. 1998; 91(11): 727-32.

13. Ifudu O, Dawood $M$, Homel $P$, et al. Timing of initiation of uremia therapy and survival in patients with progressive renal disease. Am J Nephrol. 1998; 18(3): 193-8. doi: 10.1159/000013336

14. Roubicek $C$, Brunet $P$, Huiart $L$, et al: Timing of nephrology referral: Influence on mortality and morbidity. Am J Kidney Dis. 2000; 36(1): 35-41. DOI: 10.1053/ajkd.2000.8241.

15. Sesso R, Belasco AG. Late diagnosis of chronic renal failure and mortality on maintenance dialysis. Nephrol Dial Transplant. 1996; 11(12): 2417-20.

16. Fink JC, Burdick RA, Kurth SJ, et al. Significance of serum creatinine values in new end-stage renal disease patients. Am J Kidney Dis. 1999; 34(4): 694701. doi: 10.1016/S0272-6386(99)70395-1.

17. Kidney Disease; Improving Global Outcomes Clinical Practice Guidelines: Official Journal of the International Society of Nephrology (Kidney International). 2012; 2 (Suppl 1): 2012.

18. Cooper BA, Branley $P$, Bulfone $L$, et al. A randomized controlled trial of early versus late initiation of dialysis. N Engl J Med. 2010; 363(7), 609-19. doi: 10.1056/NEJMoa1000552.

19. Sawhney S, Djurdjev O, Simpson K, et al. Survival and dialysis initiation; comparing British Columbia and Scotland registries. Nephrol Dial Transplant. 2009; 24(10): 3186-92. doi: 10.1093/ndt/gfp189.

20. Clark WF, Na Y, Rosansky SJ, et al. Association between estimated glomerular filtration rate at initiation of dialysis and mortality. CMAJ 2011; 183(1): 47-53. doi:10.1503/cmaj.100349

\section{E-mail: jwad78@gmail.com Received Mar. 18 2018 Accepted Jun. 26 2018}

